\title{
ALKALINE LEACHING OF LOW ZINC CONTENT IRON-BEARING SLUDGES
}

\begin{abstract}
Various types of waste materials containing zinc (e.g. dusts and sludges from gas dedusting process) are obtained in steel industry. The contents of $\mathrm{Zn}$ in these materials may vary considerably. Even a low concentration of zinc in recirculated products precludes their recycling in ferrous metallurgy aggregates. Long storage of this type of material can lead to contamination of soil and water by zinc compounds which can be leached out by acid rain, for example. This paper focuses on research involving alkaline leaching tests of low zinc content iron-bearing materials. These tests were preceded by the analysis of the elemental, phase and grain size composition, and analysis of the thermodynamic conditions of the leaching process. The main aim of research was to decrease the content of the zinc in the sludge to the level where it is suitable as an iron-bearing material for iron production $(\sim 1 \% \mathrm{Zn})$. Leaching at elevated temperatures $(368 \mathrm{~K}, 60 \mathrm{~min})$ has led to a decrease in the zinc content in the sludge of about $66 \%$. The research revealed that long hour leaching $(298 \mathrm{~K}, 100$ hours) carried out at ambient temperatures caused a reduction in zinc content by $60 \%$ to the value of $1.15-1.2 \% \mathrm{Zn}$.
\end{abstract}

Keywords: sludge, dust, alkaline leaching, Zn recovery, recycling

\section{Introduction}

In recent years world's production of refined zinc was about 12.5 million tonnes per year, about $30 \%$ of which was metal produced from recycled materials $[1,2]$. The iron and steel industries produce large quantities of waste with significant zinc content. The highest $\mathrm{Zn}$ content is observed in the dust from electric arc furnaces (EAF: 22 - 33\%), and a much lower content can be observed in dust and sludges from basic oxygen furnaces (BOF: 0.5 - 8\%) [3, 4]. Sludges from BOF are usually stored for a long time under conditions allowing the atmospheric effects. Performed tests [5] indicate the possibilities of leaching the significant amounts of zinc and their penetration into the soil and groundwater. The recovery of zinc from such a material is consistent with the policy of sustainable development and helps to reduce the environmental load of stored waste. After removal of zinc, waste becomes an excellent iron-bearing material that can be used as a feed component for the production of iron and steel.

The recovery of zinc from recycled materials can be generally divided into two types of methods - pyro and hydrometallurgical. The first one includes the Waelz process, Imperial Smelting Process and a number of others (Ausmelt, Enviroplas, Rapid). The group of hydrometallurgical methods includes acid leaching with either $\mathrm{H}_{2} \mathrm{SO}_{4}$ or $\mathrm{HCl}$, ammonia leaching, alkaline leaching and methods using the ion exchanging processes. An important advantage of alkaline leaching is that only zinc and lead pass into the solution. Reactions between the iron or its compounds and $\mathrm{NaOH}$ occur in a limited range. Unlike acid leaching, there is no need to remove the iron compounds from leached solution. Alkaline leaching requires highly concentrated leaching solution, elevated temperatures and can be done effectively at high ratios of the liquid/solid phases. Although $\mathrm{NaOH}$ is the basic reagent in this method, it can be found in the literature, that there is also the possibility of using $\mathrm{KOH}, \mathrm{LiOH}$ or $\mathrm{Ba}(\mathrm{OH})_{2}$ solutions [6]. Standard procedure after the zinc transfer into solution is electrolysis and deposition of $\mathrm{Zn}$ at the cathode [7]. The recovery of zinc in this method may be as high as $95 \%$ [8]. The aim of the research was to decrease the content of the zinc in the sludge to the level where it is suitable as ironbearing material for iron production. In many industrial plants that content is determined to be around $1 \%$.

\section{Materials and methods}

\subsection{Analysis of the raw material}

A sample of a sludge (BOF) obtained from purification of gases from steelmaking plants has been tested in this study. The contents of the most significant components were: $\mathrm{Fe}-58.9 \%$, $\mathrm{Zn}-2.82 \%, \mathrm{CaO}-6.14 \%, \mathrm{SiO}_{2}-1.9 \%, \mathrm{Na}_{2} \mathrm{O}-1.62 \%$. The sludge was subjected to the analysis of X-ray fluorescence spectrometer EDXRF - EDS spectrum is shown in Figure 1.

In order to determine the mineralogical composition of the material X-ray diffraction phase analysis was made. The diffraction pattern is shown in Figure 2. The obtained results indicate that the sludge contains mainly various forms of iron ( $\mathrm{Fe}, \mathrm{FeO}, \mathrm{Fe}_{2} \mathrm{O}_{3}$ and $\mathrm{Fe}_{3} \mathrm{O}_{4}$ ) and $\mathrm{ZnO}$. The fact is that the tested material is characterised by relatively low zinc content, and it is not present, at least partly, as zinc ferrite $\left(\mathrm{ZnFe}_{2} \mathrm{O}_{4}\right)$, contrary

* AGH UNIVERSITY OF SCIENCE AND TECHNOLOGY, DEPARTMENT OF PHYSICAL CHEMISTRY AND METALLURGY OF NON-FERROUS METALS, FACULTY OF NON-FERROUS METALS, AL. A. MICKIEWICZA 30, 30-059 KRAKÓW, POLAND

\# Corresponding author: krzygar@agh.edu.pl 
to many other similar materials which processing methods are discussed in the literature [9]. It was decided to perform a sieve analysis of the studied material, followed by an elemental composition analysis of selected material fractions. Size fraction analysis results are given in Table 1 . It can be seen that analysed sludge is a material in which over $60 \%$ of its weight is in the $0.4-0.1 \mathrm{~mm}$ grain range. Of nine size fraction, three were selected for further detailed analyses:

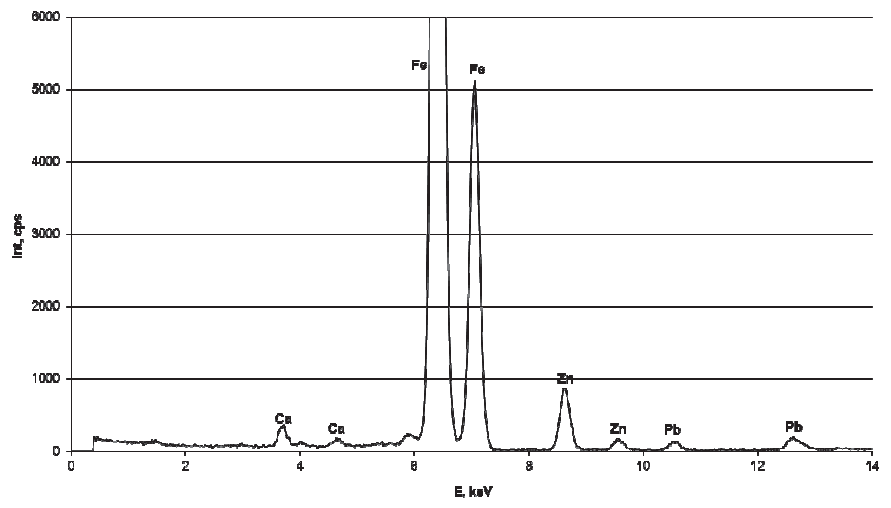

Fig. 1. EDS of original sample of sludge

$+0.63 \mathrm{~mm}-$ coarse sludge fraction

0.16-0.125 - medium grain fraction

0.09-0.071 - fine fraction

The first two fractions have the highest share in the analyzed material, and the third fraction is one of three fine fraction (less than $0.1 \mathrm{~mm}$ ), whose participation in the sludge is very similar.

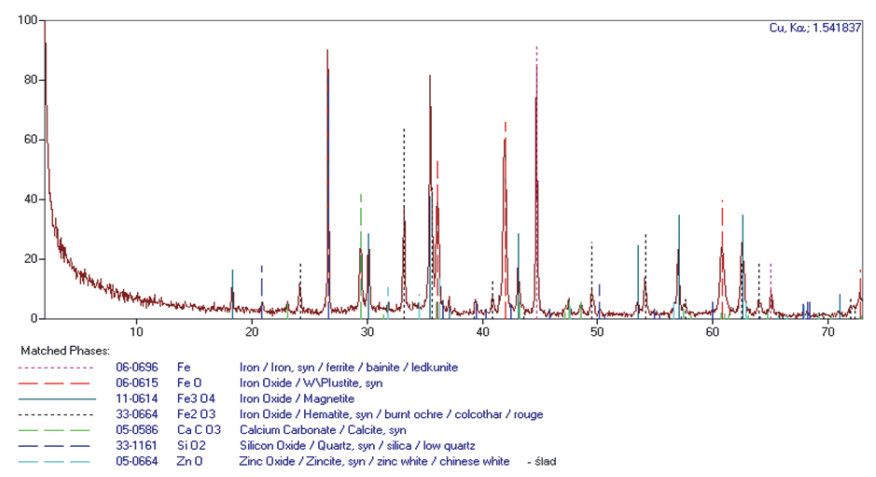

Fig. 2. X-ray diffraction phase analysis of iron-zinc sludge sample

TABLE 1

Results of grain size range analysis of studied material

\begin{tabular}{|c|c|}
\hline \hline $\begin{array}{c}\text { grain range, } \\
{[\mathrm{mm}]}\end{array}$ & {$[\%]$} \\
\hline+0.63 & 14.88 \\
\hline $0.63-0.4$ & 13.65 \\
\hline $0.4-0.25$ & 13.85 \\
\hline $0.25-0.16$ & 8.56 \\
\hline $0.16-0.125$ & 27.08 \\
\hline $0.125-0.1$ & 10.74 \\
\hline $0.1-0.09$ & 4.04 \\
\hline $0.09-0.071$ & 3.46 \\
\hline $0.071-0$ & 3.74 \\
\hline
\end{tabular}

These fractions were analysed with a scanning electron microscope and an X-ray microprobe. These studies aimed at a qualitative analysis of the elemental composition of the studied sludge and at preparing elements distribution analyses in a selected area. Three selected sludge fractions were analysed. Figure 3 shows images of a coarse sludge fraction (a), a medium grain fraction (b) and a fine fraction (c), magnified 200 times. EDSs were performed for these fields, showing presence of specific elements in studied grain fractions. An exemplary EDS for the coarse sludge fraction is shown in Figure 4.

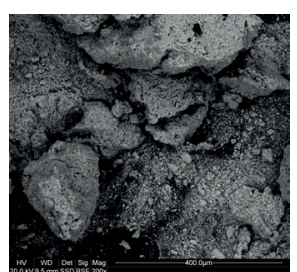

a)

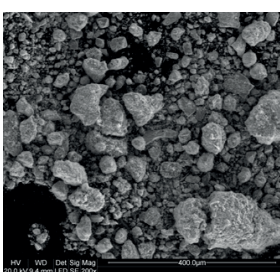

b)

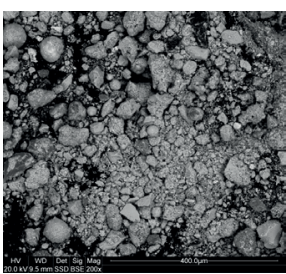

c)
Fig. 3. Micrographs of a coarse sludge fraction (a), a medium grain fraction (b) and a fine fraction (c)

When analysing EDSs performed for individual sludge grain fractions it can be concluded that they are characterised by a similar elemental composition. Peak heights corresponding to zinc content in the analysed material are in all cases very similar, so this can be a basis for a conclusion that this metal is present in each analysed fraction at a similar level. The images of the fine and the medium grain fractions indicate presence of small amounts of lead and sulphur that were not recorded in a coarse fraction. The coarse fraction, on the other hand, contains manganese which is not observed in two remaining fractions of the analysed material. The detailed digital data on content of individual elements obtained from EDS analysis is provided in Table 2.

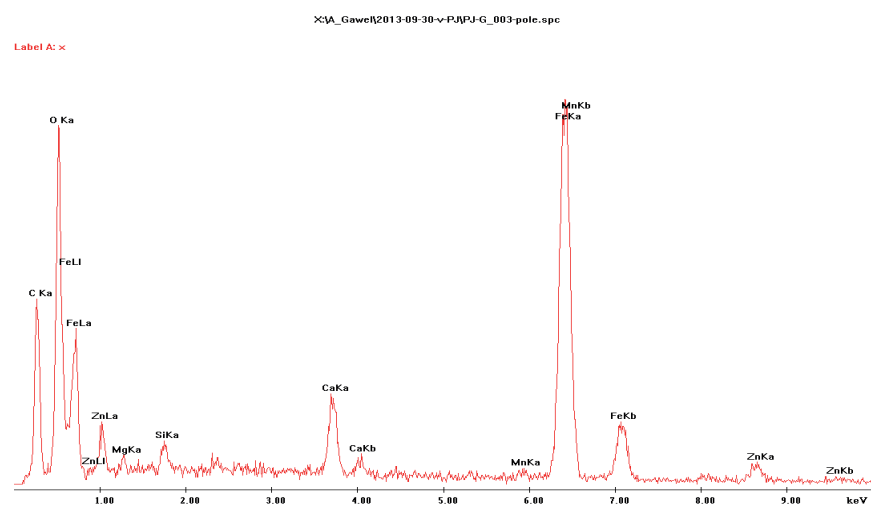

Fig. 4. EDS of the coarse sludge fraction

TABLE 2

Elemental composition of analysed sludge

\begin{tabular}{|c|c|c|c|}
\hline \hline \multirow{2}{*}{ element } & \multicolumn{3}{|c|}{ content, [\%] } \\
\cline { 2 - 4 } & coarse sludge & medium grain & fine fraction \\
\hline $\mathrm{O}$ & 32,09 & 31,98 & 33,29 \\
\hline $\mathrm{Mg}$ & 0,96 & 0,70 & 0,97 \\
\hline
\end{tabular}




\begin{tabular}{|c|c|c|c|}
\hline $\mathrm{Al}$ & - & 0,28 & - \\
\hline $\mathrm{Si}$ & 1,24 & 1,54 & 1,94 \\
\hline $\mathrm{S}$ & - & 0,14 & 0,28 \\
\hline $\mathrm{Pb}$ & - & 0,84 & 0,69 \\
\hline $\mathrm{Ca}$ & 3,86 & 4,35 & 4,44 \\
\hline $\mathrm{Mn}$ & 1,10 & - & - \\
\hline $\mathrm{Fe}$ & 58,82 & 57,58 & 59,40 \\
\hline $\mathrm{Zn}$ & 3,37 & 2,91 & 2,71 \\
\hline
\end{tabular}

\subsection{Thermodynamic conditions of the leaching process}

The performed analysis indicates presence of $\mathrm{ZnO}$ and iron in its metallic form, and of $\mathrm{FeO}, \mathrm{Fe}_{2} \mathrm{O}_{3}$, and $\mathrm{Fe}_{3} \mathrm{O}_{4}$. Therefore, it was decided to perform a thermodynamic analysis to determine possible course of selected chemical reactions during alkaline leaching of the studied sludge. For zinc, a number of chemical reactions were analysed, with $\mathrm{ZnO}$ being a substrate, and products including one of the following ions: $\mathrm{ZnOH}^{+}, \mathrm{ZnO}_{2}^{2-}$, $\mathrm{Zn}(\mathrm{OH})_{3}^{-}$or $\mathrm{Zn}(\mathrm{OH})_{4}^{2-}$. For selected reactions, a change in Gibbs free energy at $298 \mathrm{~K}$ was calculated.

$$
\begin{array}{ll}
\mathrm{ZnO}+\mathrm{H}_{2} \mathrm{O}+\mathrm{OH}^{-}=\mathrm{Zn}(\mathrm{OH})_{3}^{-} & \Delta \boldsymbol{G}_{298}^{0}=14.89 \mathrm{~kJ}(1) \\
\mathrm{ZnO}+\mathrm{H}_{2} \mathrm{O}+2 \mathrm{OH}^{-}=\mathrm{Zn}(\mathrm{OH})_{4}^{2-} \Delta_{298}^{0}=7.94 \mathrm{~kJ}(2) \\
\mathrm{ZnO}+\mathrm{H}^{+}+2 \mathrm{OH}^{-}=\mathrm{Zn}(\mathrm{OH})_{3}^{-} & \Delta \boldsymbol{G}_{298}^{0}=-61.39 \mathrm{~kJ}(3) \\
\mathrm{ZnO}+\mathrm{H}^{+}+3 \mathrm{OH}^{-}=\mathrm{Zn}(\mathrm{OH})_{4}^{2-} & \Delta \boldsymbol{G}_{298}^{0}=-68.43 \mathrm{~kJ}(4) \\
\mathrm{ZnO}+H^{+}=\mathrm{ZnOH}^{+} & \Delta \boldsymbol{G}_{298}^{0}=-19.31 \mathrm{~kJ}(5) \\
\mathrm{ZnOH}+2 \mathrm{OH}^{-}=\mathrm{Zn}(\mathrm{OH})_{3}^{-} & \Delta \boldsymbol{G}_{298}^{0}=-49.60 \mathrm{~kJ}(6) \\
\mathrm{ZnOH}+3 \mathrm{H}^{-}=\mathrm{Zn}(\mathrm{OH})_{4}^{2-} & \Delta \boldsymbol{G}_{298}^{0}=-56.64 \mathrm{~kJ}(7) \\
\mathrm{Zn}(\mathrm{OH})_{3}^{-}+\mathrm{OH}^{-}=\mathrm{Zn}(\mathrm{OH})_{4}^{2-} & \Delta \boldsymbol{G}_{298}^{0}=-7.05 \mathrm{~kJ}(8)
\end{array}
$$

Calculations of $\Delta G_{T}^{0}$ for the above-mentioned chemical reactions were performed with the HSC Chemistry (ver. 6.12) application and the literature data $[10,11]$. The obtained results indicate that reactions (1-4) are crucial for alkaline leaching, essential for the whole process to occur. In these reactions $\mathrm{ZnO}$ present as a substrate migrates to the solution. For leaching at relatively low hydroxide levels, it is possible for the reaction (5) to occur, being a condition for subsequent reactions (6-8). The environment in reactions (3-5) contains $\mathrm{H}^{+}$ions. They can therefore occur only when these ions are present in the leaching solution, and the process kinetics will be proportional to hydrogen cation levels in the solution.

It can be assumed that the source of these ions in the analysed process will be the water dissociation process. Water is a very weak electrolyte that undergoes autoionisation.
The concentration dissociation constant is described by the following formula:

$$
\mathrm{K}_{\mathrm{H}_{2} \mathrm{O}}=\frac{\left[\mathrm{H}^{+}\right]\left[\mathrm{OH}^{-}\right]}{\left[\mathrm{H}_{2} \mathrm{O}\right]}
$$

where $\left[\mathrm{H}_{2} \mathrm{O}\right]$ means the molar concentration of undissociated water. The molar concentration of pure water $\left[\mathrm{H}_{2} \mathrm{O}\right]$ is relatively high (about $55.6 \mathrm{~mol} / \mathrm{dm}^{3}$ ), and depends on the temperature only to a small extent. The ionic product of water $\left(\mathrm{K}_{\mathrm{W}}=\mathrm{K}_{\mathrm{H}_{2} \mathrm{O}} \cdot\left[\mathrm{H}_{2} \mathrm{O}\right]\right)$ is also a constant value for a specific temperature. The $\mathrm{K}_{\mathrm{w}}$ values for temperatures ranging from 273 to $373 \mathrm{~K}$ are listed in Table 3 [12].

TABLE 3

Ionic product of water versus temperature

\begin{tabular}{|c|c|}
\hline \hline $\mathrm{T},[\mathrm{K}]$ & $\mathrm{K}_{\mathrm{w}},\left[\left(\mathrm{mol} / \mathrm{dm}^{3}\right)^{2}\right]$ \\
\hline 273 & $0.114 \cdot 10^{-14}$ \\
\hline 298 & $1.008 \cdot 10^{-14}$ \\
\hline 303 & $1.471 \cdot 10^{-14}$ \\
\hline 313 & $2.916 \cdot 10^{-14}$ \\
\hline 323 & $5.476 \cdot 10^{-14}$ \\
\hline 348 & $20.420 \cdot 10^{-14}$ \\
\hline 373 & $51.300 \cdot 10^{-14}$ \\
\hline
\end{tabular}

The presented data shows clearly that the increase in the temperature is accompanied by the increase in the ionic product of water, particularly at 348-373 K, when this product is from 20 to 50 times higher than the one at $298 \mathrm{~K}$. This means that at increased temperatures the $\mathrm{H}^{+}$ions level increases from above 4 to 7 times versus the one at $298 \mathrm{~K}$, and therefore, the conditions are much better for the reaction to occur (3-5).

Figure 5 shows a diagram illustrating areas of thermodynamic phase stability in the $\mathrm{Zn}-\mathrm{H}_{2} \mathrm{O}$ configuration [13]. It can be clearly seen that in solutions of $\mathrm{pH}$ exceeding 9 $\mathrm{Zn}(\mathrm{OH})_{3}^{-}$ions can appear, while when $\mathrm{pH}$ exceeds 11, the solution can contain $\mathrm{Zn}(\mathrm{OH})_{4}^{2-}$ ions. For $\mathrm{pH}$ ranging from 7 to 10 , that is, for slightly alkaline solutions, a small amount of $\mathrm{ZnOH}{ }^{+}$can be present, so the reaction (5) can occur.

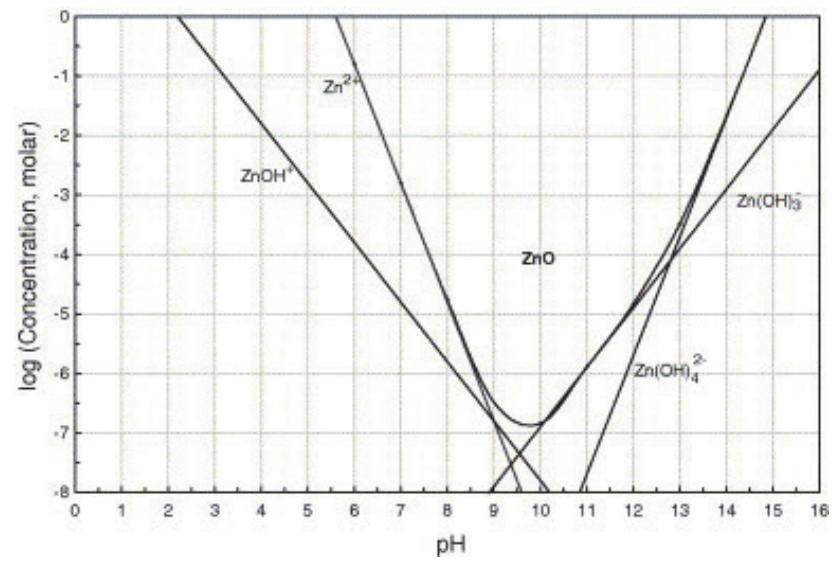

Fig. 5. Solubility of $\mathrm{ZnO}$ as a function of $\mathrm{pH}$, at $298 \mathrm{~K}$ [13]

In the literature, $\mathrm{ZnO}_{2}^{2-}$ present in the $\mathrm{Zn}-\mathrm{H}_{2} \mathrm{O}$ configuration is often identified with the $\mathrm{Zn}(\mathrm{OH})_{4}^{2-}$ ion, and 
a difference in stoichiometry results from two $\mathrm{H}_{2} \mathrm{O}$ molecules absorbed by the $\mathrm{ZnO}_{2}^{2-}$ ion. Figure 6 shows the area of the $\mathrm{ZnO}_{2}^{2-}$ ion presence at $298 \mathrm{~K}$ for the zinc level of $0.01 \mathrm{~mol} / \mathrm{dm}^{3}$. The mentioned ion appears at $\mathrm{pH}$ exceeding 13.65.

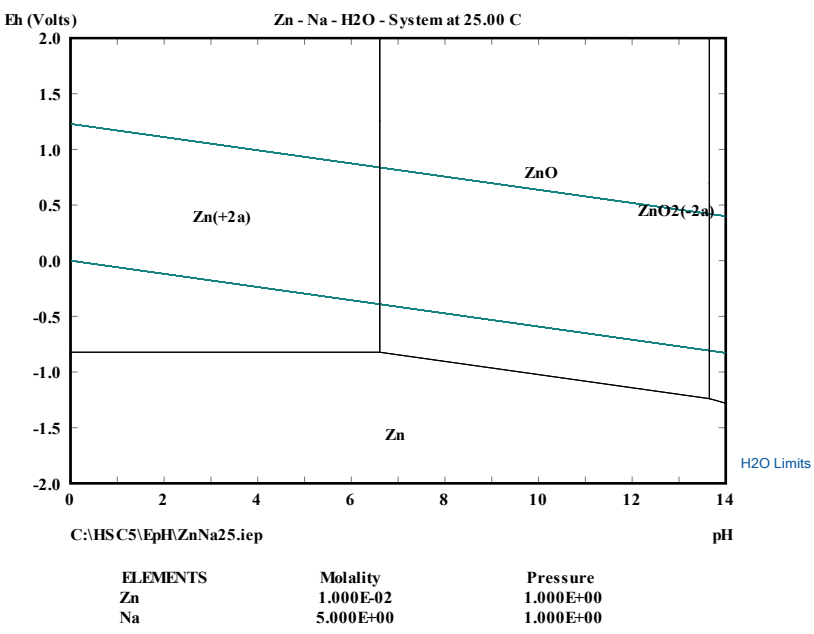

Fig. 6. $\mathrm{E}-\mathrm{pH}$ diagram in $\mathrm{Zn}-\mathrm{H}_{2} \mathrm{O}$ system at $298 \mathrm{~K}$

At higher temperatures, it is possible for higher zinc levels to appear in the solution in the form of this anion. Calculations of E-pH diagrams performed for 298, 343 and $368 \mathrm{~K}$ for different concentrations of zinc ions allowed to achieve the $\mathrm{pH}$ value at which the above-mentioned ion starts to appear. Fig. 7 presents a relationship between logarithm for the zinc concentration in the solution and $\mathrm{pH}$ of the solution.

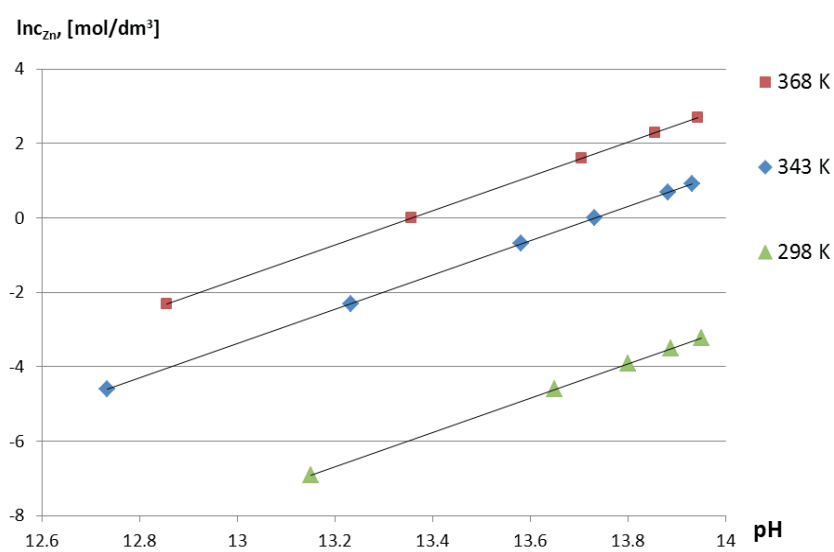

Fig. 7. Logarithm of the concentration of zinc in solution as a function of $\mathrm{pH}$ limit value at 298, 343 and $368 \mathrm{~K}$

At high hydroxide levels in the leaching solutions and increased temperatures, zinc can be present in the solution as the $\mathrm{ZnO}_{2}^{2-}$ ion at levels reaching even several $\mathrm{mol} / \mathrm{dm}^{3}$ of the solution.

For alkaline leaching of materials containing iron oxide in the second and third oxidation state, there is a low possibility for its migration into the solution and its presence there in its ion form. Solubility diagrams for various iron ion forms (bi and trivalent) shown in Fig. 8 [13] indicate this element can be present at the level of ca. $10^{-4} \mathrm{~mol} / \mathrm{dm}^{3}$ at $\mathrm{pH}$ close to 14 .
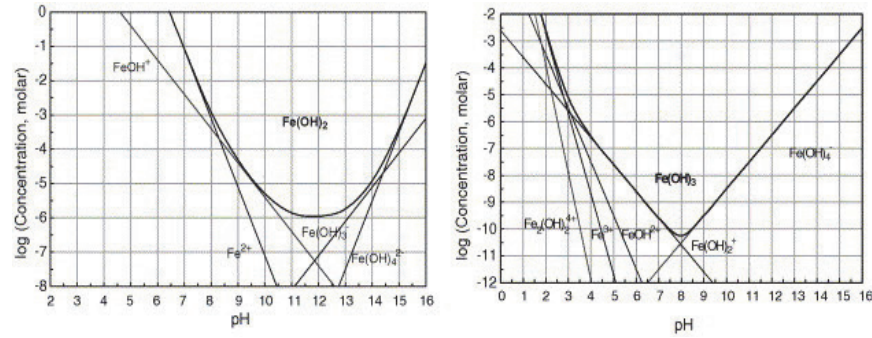

Fig. 8. Solubility of $\mathrm{FeO}$ and $\mathrm{Fe}_{2} \mathrm{O}_{3}$ as a function of $\mathrm{pH}$, at $298 \mathrm{~K}$ [13]

In the specific conditions, the $\mathrm{FeO}_{2}^{-}$ion appears in the $\mathrm{Fe}-\mathrm{H}_{2} \mathrm{O}$ configuration, which in the literature is treated similarly to the $\mathrm{Fe}(\mathrm{OH})_{4}^{-}$anion, and the difference results from two water molecules added to $\mathrm{FeO}_{2}^{-}$. However, the area of the $\mathrm{FeO}_{2}^{-}$anion presence is relatively limited and depends on the solution $\mathrm{pH}$, the Fe ion level and the temperature. Fig. 9 shows the E-pH diagram calculated for $298 \mathrm{~K}$ and the iron level of $10^{-4} \mathrm{~mol} / \mathrm{dm}^{3}$. In currentless conditions, $\mathrm{FeO}_{2}^{-}$ions are present only above $\mathrm{pH}$ of 13.8 .

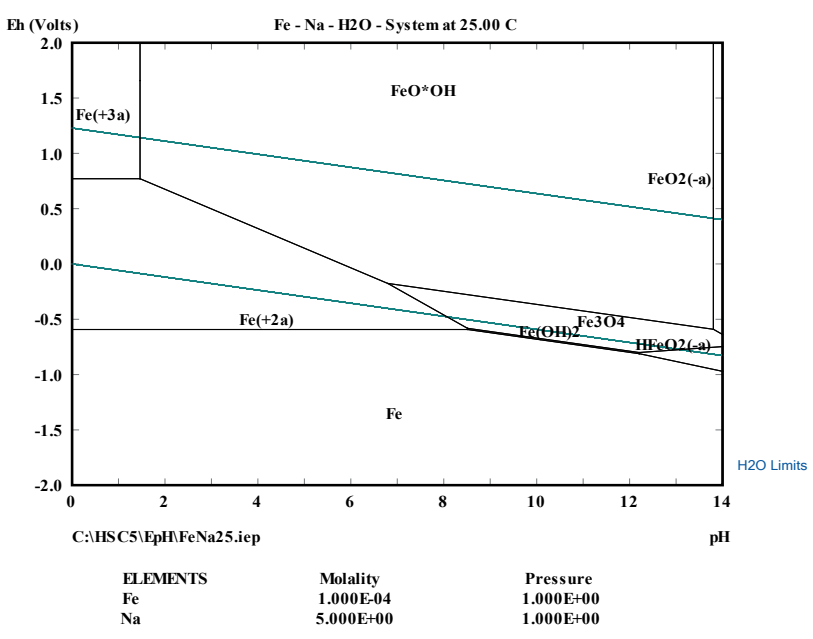

Fig. 9. $\mathrm{E}-\mathrm{pH}$ diagram in $\mathrm{Fe}-\mathrm{H}_{2} \mathrm{O}$ system at $298 \mathrm{~K}$

The iron levels in the solution were calculated for limiting $\mathrm{pH}$ values at 298, 343 and $368 \mathrm{~K}$, facilitating appearance of the $\mathrm{FeO}_{2}^{-}$ions. Results are present in Fig. 10.

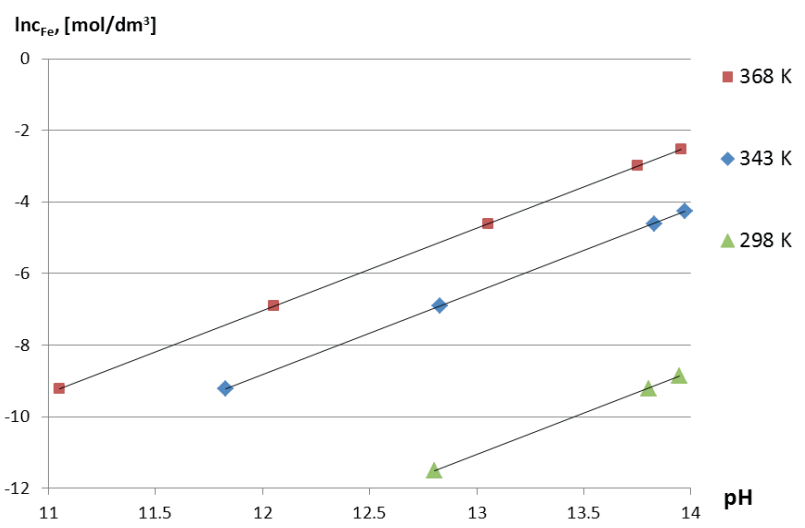

Fig. 10. Logarithm of the concentration of $\mathrm{Fe}$ in solution as a function of $\mathrm{pH}$ limit value at 298, 343 and $368 \mathrm{~K}$ 
The obtained results indicate that during alkaline leaching of material containing iron, the possibility for large iron quantities being transferred into the solution is very low. As calculated E-pH diagrams apply to equilibrium conditions, it can be assumed that even with relatively high hydroxide levels in the leaching solution ( $\mathrm{pH}$ approaching 14) and raised temperatures the expected iron levels in the solutions will be below $10^{-2} \mathrm{~mol} / \mathrm{dm}^{3}$.

\subsection{Methodology}

Samples of the sludge with a mass of 20 grams were leached in a borosilicate glass beaker with a solution of $\mathrm{NaOH}$ or $\mathrm{KOH}$ of a predetermined concentration in an amount corresponding to the adopted mass ratio of the liquid phase to the solid phase. The vessel was placed on a hot plate providing a stable temperature of the process. The temperature was measured by a thermometer placed in the solution. Leach solution was stirred with a mechanical stirrer rotating in all of the tests at a constant speed of $300 \mathrm{rpm}$. After a predetermined amount of time, the solution after leaching was filtered, the resulting solid residue was washed on a filter with distilled water, dried, and then analyzed for zinc content. In all tests atomic absorption spectrometer (AAS) was used for determining the concentration of zinc in the samples.

Two series of tests were performed: at $343 \mathrm{~K}, 368 \mathrm{~K}$ and under pressure, using autoclave at $403 \mathrm{~K}$, whose purpose was to determine the optimal parameters for leaching, and longterm trials conducted at a temperature of $298 \mathrm{~K}$, which were to answer the question about the possibility of removing zinc in a low-temperature process. In the first step, the leaching time was varied at a fixed concentration of hydroxides, liquid/solid mass ratio and the temperature. The optimum leaching time was determined on the basis of satisfactory decrease in the content of zinc in the sample. In an analogous manner other leaching parameters were varied, to obtain finally the whole data set at which the process occurs with maximum efficiency. In the second series of tests, sludge was leached at $298 \mathrm{~K}$ for a period of 10 to 100 hours at hydroxides concentration and liquid/solid mass ratio determined in the first series of tests.

\section{Results and discussion}

\subsection{Tests at elevated temperature}

The aim of the study was to verify the applicability of $\mathrm{KOH}$ and $\mathrm{NaOH}$ solutions to leach $\mathrm{Zn}$ from iron-bearing materials with a low zinc content, and to determine the effectiveness of these reagents. Based on the analysis of reports found in the literature [13-15] the initial parameters of the leaching solution and process conditions were defined. Samples of the material were leached with solutions of hydroxides with a concentration of $5 \mathrm{~mol} / \mathrm{dm}^{3}$ at $343 \mathrm{~K}$, and the mass ratio of the liquid phase to the solid phase equal to the 5. Experiments were run for 60 , 120 and 180 minutes respectively, samples of the sludge after an appropriate time were analyzed for the content of $\mathrm{Zn}$. The results are shown in Figure 11.

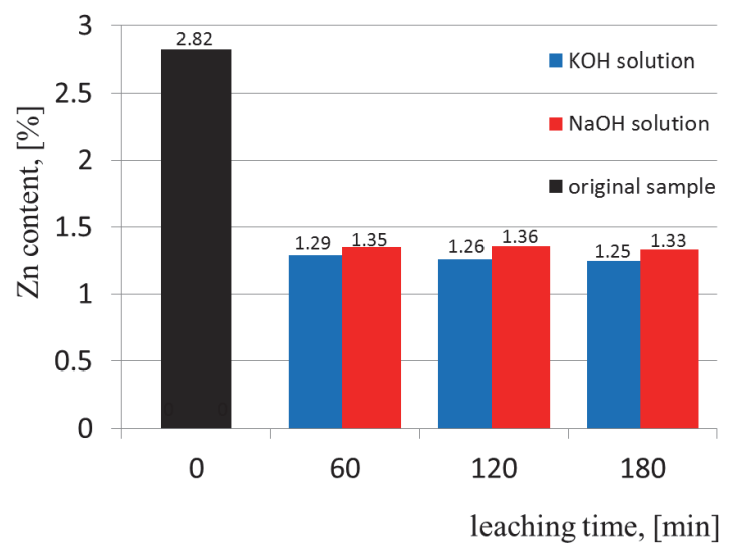

Fig. 11. $\mathrm{Zn}$ content in the original material and in solid residue after leaching $(5 \mathrm{~mol} / \mathrm{dm} 3,1 / \mathrm{s}=5,343 \mathrm{~K})$

Analysis of the results indicates that the optimum leaching time is around 60 minutes. Longer duration of the process does not result in a noticeable decrease of the zinc content in the material after leaching. However, it was planned to determine the possibility to reduce the content of $\mathrm{Zn}$ in the material to about $1 \%$ (acceptable value for the use of sludge as the charge component to iron and steel industry) consequently it was decided to carry out further studies at higher temperatures ( 368 and $403 \mathrm{~K}$ ) for a fixed time of 60 minutes. The results of these tests were compared with the result of leaching at $343 \mathrm{~K}$ (Figure 12). A significant effect of temperature on the leaching process is noticeable in the case of temperature equal to $368 \mathrm{~K}$. The increase in temperature from $343 \mathrm{~K}$ to $368 \mathrm{~K}$ results in a decrease of the zinc content in the sample by about $10 \%$. At highest temperature the phenomenon of decline in the efficiency of the leaching process was observed. According to literature data, when the temperature exceeds $393 \mathrm{~K}$ zinc dissolved under these conditions reacts with iron compounds present in the slurry, and therefore precipitation of zinc ferrite in the solid form takes place [13].

Subsequently, it was decided to investigate the effect of concentration of the leaching solution on the zinc content in the sample after leaching. Thus constant parameters were: time, temperature and the ratio of liquid phase to a solid phase (respectively $60 \mathrm{~min} ., 368 \mathrm{~K}, 5$ ), and another attempt was carried out at higher concentrations of $\mathrm{KOH}$ and $\mathrm{NaOH}$ solutions $-7 \mathrm{~mol} / \mathrm{dm}^{3}$. The results show a minimal effect of the concentration of the leaching solution on the contents of $\mathrm{Zn}$ in the sample at a constant mass ratio (liquid/solid). In the case of $\mathrm{KOH}$ solution, $\mathrm{Zn}$ content decreased from 1.16 to $1.15 \%$, and there was no change in the content of zinc $(1.12 \%)$ when $\mathrm{NaOH}$ solution was used. With increasing of hydroxide concentration, density of solution increases, and at constant $1 / \mathrm{s}$ mass ratio the reduction of the volume of the leaching solution is observed. This leads to no growth in the efficiency of the zinc removal from the sludge. 


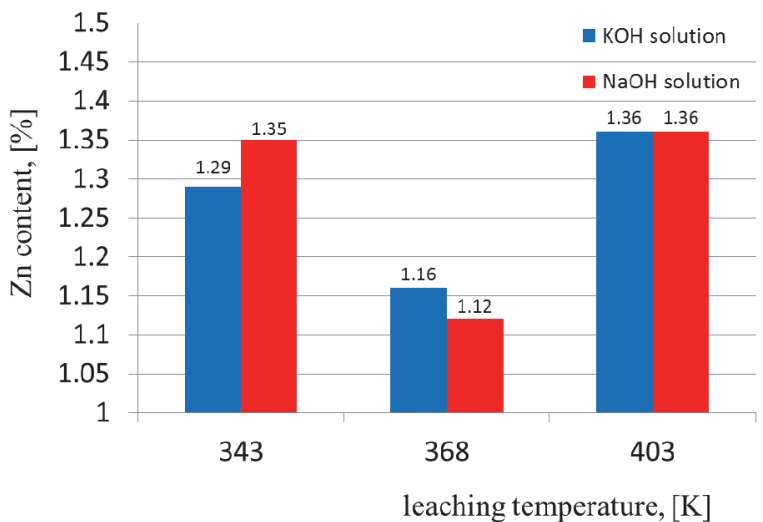

Fig. 12. Zn content in the sample after leaching as a function of the process temperature $(60 \mathrm{~min} ., 5 \mathrm{~mol} / \mathrm{dm} 3,1 / \mathrm{s}=5)$

Therefore, it was agreed to carry out the leaching process at unchanged concentration of hydroxides $\left(5 \mathrm{~mol} / \mathrm{dm}^{3}\right)$ at mass ratio equal to the 10 , and probably optimal process temperature equal to $368 \mathrm{~K}$. The results were compared in Figure 13 with leaching at mass ratio of the 5 .

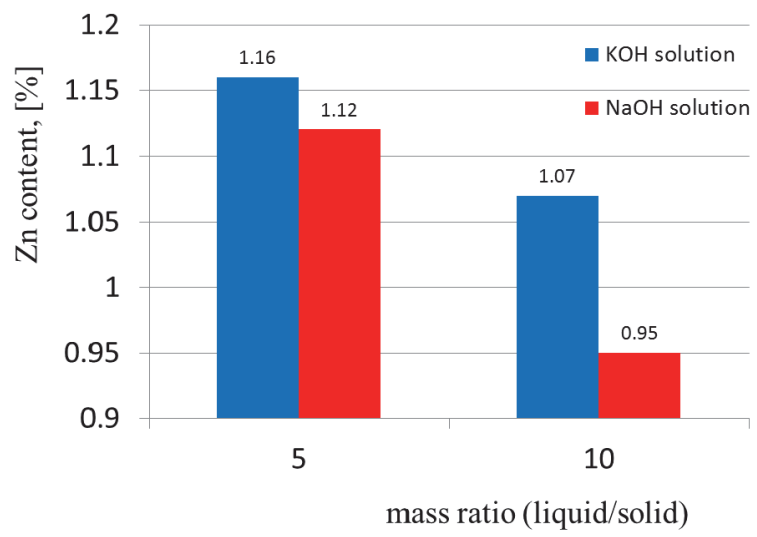

Fig. 13. Zn content in the sample after leaching as a function of the mass ratio (liquid/solid) (60 min., $5 \mathrm{~mol} / \mathrm{dm} 3,368 \mathrm{~K}$ )

It can be seen that after leaching a material with desired content of $\mathrm{Zn}$ is obtained, slightly in excess of $1 \%(\mathrm{KOH}$ solution), or already below this level ( $\mathrm{NaOH}$ solution). Due to the positive results obtained in the experiment with mass ratio equal to the 10 , it was decided to perform leaching at three different temperatures $(343,368$ and $403 \mathrm{~K})$. Other leaching parameters were assumed at the level of the previous test i.e. 60 minutes, $5 \mathrm{~mol} / \mathrm{dm}^{3}$. Results obtained for temperatures selected were compared in Figure 14.

Obtained in presented study results indicate that the optimum value of the leaching time is 60 minutes, and the temperature of the process should be kept at $368 \mathrm{~K}$. A very important factor is the mass ratio - an increase of this parameter causes a noticeable increase in process efficiency. The change in the concentration of hydroxides does not affect apparently on the leaching process in the case of low-zinc material processing.

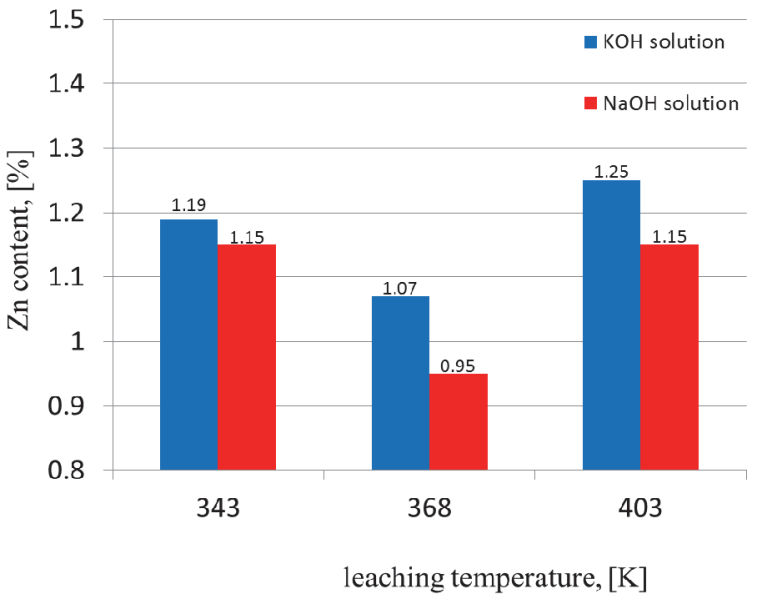

Fig. 14. Zn content in the sample after leaching as a function of the process temperature $(60 \mathrm{~min} ., 5 \mathrm{~mol} / \mathrm{dm} 3,1 / \mathrm{s}=10)$

\section{Tests at ambient temperature}

In this part of the study it was decided to determine the possibility of removing zinc from the sludge by alkaline leaching at ambient temperature. The time was a variable parameter in these tests - from 10 to 100 hours. Leaching was carried out with $\mathrm{NaOH}$ and $\mathrm{KOH}$ solutions. Concentration of hydroxides was $5 \mathrm{~mol} / \mathrm{dm}^{3}$, mass ratio $(1 / \mathrm{s})$ was 10 , and temperature was $298 \mathrm{~K}$. The results of performed experiments are shown in Figure 15.

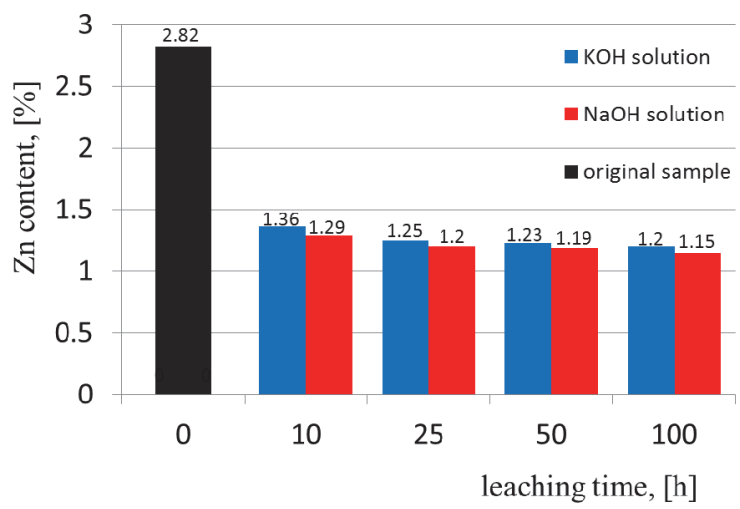

Fig. 15. $\mathrm{Zn}$ content in the original material and after leaching at ambient temperature $(5 \mathrm{~mol} / \mathrm{dm} 3,1 / \mathrm{s}=10,298 \mathrm{~K})$

Obtained results indicate a real possibility of removing zinc from sludge by the alkaline leaching process at ambient temperatures. A necessary condition for a positive effect of this kind of process is to continue leaching for a minimum of 100 hours. Although the effect of leaching is noticeable already after 10 hours of operation (removal of about $50 \%$ of the zinc contained in the sludge), it is possible to reach residual content of zinc in the sample near the level of 1 $\%$ only after about 100 hours of process. As previously stated, as far as the applicability of the sludge as charge component for the production of iron and steel is concerned, 
such a concentration is satisfactory. Leaching at ambient temperature does not need such a large energy consumption, as in the case of solutions heated to temperatures close to $368 \mathrm{~K}$, and despite much longer duration of the process, the overall expenses are much lower. As a result, this procedure can be used for the treatment of many wastes that have not been processed so far, because it has not been economic due to the high costs of leaching at elevated temperatures. An additional advantage of both presented versions of processing method is that solution after leaching almost does not contain iron nor iron compounds. Thus, this method does not lead to loss of iron and residue after leaching can be raw material in the iron and steel metallurgical plants.

\section{Conclusions}

This study confirms the possibility of using aqueous solutions of $\mathrm{KOH}$ and $\mathrm{NaOH}$ as leaching media in the processing of iron-bearing material with a low zinc content. Obtained results indicate a number of factors influencing the leaching process. Optimization of these parameters performed in the presented study results in a determination of their numerical values with respect to a leaching time, process temperature, the concentration of hydroxides, and the mass ratio of the leaching solution to the processed material. Performed tests indicate the possibility of obtaining materials with zinc content about $1 \%$, that can be used in iron and steel metallurgical industry. Long term leaching at ambient temperature also allowed to obtain a material with a zinc content at a level close to $1 \%$.

\section{REFERENCES}

[1] US Geological Survey, Mineral Commodity Summaries 2012.

[2] M.D. Gerst, T.E. Graedel, In-use stocks of metals: Status and implicaitions, Environmental Science \& Technology 42, 7038-7045 (2008).

[3] C. Caravaca, A. Cobo, F.J. Alguacil, Considerations about the recycling of EAF flue dusts as source for the recovery of valuable metals by hydrometallurgical processes, Resources Conservation and Recycling 10, 35-41 (1994).

[4] S. Kelebek, S. Yoruk, B. Davis, Characterization of basic oxygen furnace dust and zinc removal by acid leaching, Minerals Engineering 17, 285-291 (2004).

[5] K. Gargul, B. Boryczko, Removal of zinc from dusts and sludges from basic oxygen furnaces in the process of ammoniacal leaching, Archives of Civil and Mechanical Engineering 15, 179-187 (2015).

[6] V.I. Rodionova, On the Dissolution of Zinc in Alkalis, National Aeronautics and Space Administration, Washington 1965.

[7] A. Stefanova, J. Aromaa, Alkaline leaching of iron and steelmaking dust, Aalto University 2012.

[8] T. Havlik, Lecture Slides of Processing of Metallurgical Dusts by Hydrometallurgical Methods Seminar, Espoo 2009.

[9] N. Leclerc, E. Meux, J.M. Lecuire, Hydrometallurgical extraction of zinc from zinc ferrites, Hydrometallurgy 70, 175183 (2003).

[10] Selected Values of Chemical Thermodynamic Properties - Tables for the First Thirty-Four Elements in the Standard Order of Arrangement, NBS Technical Note 270-3, National Bureau of Standards, Washington 1968.

[11] E.L. Shock, D.C. Sassani, M. Willis, D.A. Sverjensky, Inorganic species in geologic fluids: correlations among standard molar thermodynamic properties of aqueous ions and hydroxide complexes, Geochim. Cosmochim. Acta 61, 907 (1997).

[12] G.J. Bignold, A.D. Brewer, B. Hearn, Specific conductivity and ionic product of water between 50 and $271{ }^{\circ} \mathrm{C}$, Trans. Faraday Soc. 67, 2419 (1971).

[13] A.J.B. Dutra, P.R.P. Paiva, L.M. Tavares, Alkaline leaching of zinc from electric arc furnace steel dust, Minerals Engineering 19, 478-485 (2006).

[14] C. Jarupisitthorn, T. Pimtomg, G. Longhongkum, Investigation of kinetics of zinc leaching from electric arc furnace dust by sodium hydroxide, Material Chemistry and Physics 77, 531532 (2002).

[15] J. Antrekowitsch, H. Antrekowitsch, Hydrometallurgically Recovering Zinc from Electric Arc Furnace Dusts, JOM 12, 26-28 (2001). 
